\title{
The invariants of the Hilbert transform data wavelet analysis
}

\author{
P.M. Mazurkin'1 \\ ${ }^{1}$ Department of environmental engineering, Volga State University of Technology, \\ Yoshkar-Ola, Republic of Mari El, Russian Federation \\ Corresponding author: kaf_po@mail.ru
}

\begin{abstract}
Process of identification of steady laws in the form of asymmetric wavelet signals is stated. Thus the wave equations with variables amplitude and the period of fluctuation are designed from the generalized invariant and its fragments. This invariant according to Hilbert is reasonable as the biotechnical law generalizing almost all known laws of distribution. The essence, structure and parameters of the biotechnical law and its fragments is in detail shown. For identification statistical data of measurements in the form of tabular model are required. Then Hilbert's 23rd problem is solved as a problem of statistical (probabilistic) modeling. At the first stage the variation of functions is reduced to conscious selection of steady laws and designing on their basis of steady wave regularities adequate to studied natural processes. At the second stage there is a consecutive structural and parametrical identification of regularities on statistical selections by the sum asymmetric wavelets. The decision 23-oh Hilbert's problems by the one and only universal algebraic wave equation, in the general form on Descartes's hypothesis where half of amplitude and the period are displayed by the biotechnical law is given. Everyone wavelet this algebraic equation contains two fundamental physical constants - the number $e$ of time or Napier and the number $\pi$ of space or Archimedes.

Examples of modeling, identification of the amount of asymmetric wavelet signal behavior of natural objects: the pulse of the electrocardiogram of a healthy person; natural drying samples meadow grass; mutual influence of forest cover and tilled territory; Crisis dynamics of the ruble and default 1998 y.; volume of patenting and forecast innovations in Russia until 2020 y.; dynamics of forest fires in the national park for the 1982-2011 y.; hour increments pulses alpha decay ${ }^{239} \mathrm{Pu}$ sample at the maximum of the solar eclipse; amplitude of gravitational waves from the orbital period of 10 pulsars in the model splashing Universe.
\end{abstract}

Keywords: 23-oh Hilbert's problems, algebraic wave, identification, asymmetric wavelet signals, generalized model, examples, patterns.

\section{Introduction}

On a site http://link.springer.com/journal/208 by search on words "Invariants of the Hilbert transform for 23-Hilbert problem" appeared only two links to publications [2, 3]. And for the words "Invariants of the Hilbert transform" we received 5860 links. As a result it is visible that invariants or Hilbert's bricks for the solution of the 23rd problem still aren't found.

The problem of development of methods of calculus of variations (Hilbert's 23rd problem) still isn't resolved though in this direction it was much made Hilbert [4]. 
David Hilbert's mathematical activity can conditionally be divided into two multidirectional concepts (understanding vectors):

a) the integrated equations and physics (in a general sense, including all sciences: astronomy, biology and ecology, econometrics, technology, etc.);

b) algebraic numerical fields and invariants.

Two of these vectors of understanding unite in the theory of axiomatics of Hilbert.

Thus, the axiomatics is cornerstone of both approaches - from the mathematician to the physicist-theorist (the first vector) and, on the contrary, from the experimenter to the mathematician. The approach mathematician-theorist to the development of abstract mathematics, we do not consider. On many examples (more than 100 thousand) statistical (probabilistic) modeling were convinced that the solution of the 23rd problem of Hilbert [1] - [6] is found not in mathematics or physics separately, namely in transition from experimental physics (measurement in physics, astronomy, biology and ecology, sociology and econometrics, equipment and technology) to methods of applied mathematics.

Key to understanding classical mathematics of methodology of identification of invariants offered by us on real algebraic numerical fields as to results of multiplefactor physical measurements, the heuristic statement is: "As leading principle for Hilbert the analogy to the corresponding problems for algebraic functions from one variable served" [4].

\section{Biotechnical law and its features}

Heuristically (in substantial sense) the biotechnical law is formulated as follows: in the processes of life and evolution of biological and biogenic objects over time no action is equal to counteraction.

Equality of forces of action and counteraction (under the third law of Newton) is observed in time only at the transition moment from growth to dying off, that is the case is shown as private (one-stage in time) [7] - [16].

The law of spatial interaction offered by us, without time, is briefly formulated so: Action isn't equal to counteraction. The name "biotechnical law" offered by us indicates skill of life (techne - skill, bio - life), that is this steady law (the generalized invariant according to Hilbert) is shown in those objects of research in which to some extent there is a life at the present or there are its manifestations in the past (for example, wood and wood materials). Therefore in all abiotic objects, including and star systems, skill of life has to be shown.

For engineering ecology, rational environmental management, arrangement of the natural objects, territorial managing and other types of ecological and economic activity connected with natural objects and economic systems, the sum of forces of action and counteraction making a measure of interaction of mankind with the nature passes into the general principle of the academician V.I. Vernadsky.

In our opinion, this lump of the biosphere during its evolution forms a variable power impulse of life on the planet Earth. Once again we will emphasize that we accept the direction of forces of interaction in the form of an arrow of time of S. Hawking.

Therefore the biotechnical law defines change only of scalar size of forces of interaction, without affecting the direction of these forces. 
Change of the direction of forces (for example, succession of an ecosystem or revolutionary influence of action on an ecological mode and a territory landscape) in this article isn't considered and therefore in the majority of examples receives only substantial, and only initially set hypothetical, an explanation. In other words, for a considered numerical field of the direction of forces have to be uniform.

From such comparison we can conclude that the biotechnical law considers, first of all, a quantitative ratio of forces of action and counteraction.

Thus has to be in advance (before statistical modeling) it is known that upon transitions from one cycle to another there are no changes of the direction of these interacting forces. On the basis of application of the biotechnical law in each case of researches high-quality (heuristic) and quantitative (statistical) interpretation is carried out.

It is possible to generalize, claiming that where there is an interaction, there is also a manifestation of the biotechnical law.

Now, on the basis of many other scientific works, we approve the bigger: where there is a manifestation of the biotechnical law, there probably (at least fragmentary) studying of a real cycle of uniform interaction taking into account steady laws and properties of an ideal cycle.

\section{Method of identification of the biotechnical law}

Process of identification of steady regularities of [10] different forms containing in invariants, is presented as process of the solution of a problem of statistical (probabilistic) modeling by asymmetric wavelet signals on dynamic ranks of measurements. Further the methodology of identification of steady laws of determined or wave dynamics of any process by wave functions with variables amplitude and fluctuation frequency is shown.

This section is given as the decision 23-oh Hilbert's problems by the one and only universal algebraic wave equation in the general form offered by the author and by that the hypothesis and Descartes's known concept is proved. Euler's hypothesis of universality of the sum of trigonometric functions for the description of dynamics of natural processes is proved also.

The error of measurements or quantitative representations by drawing up a numerical field, i.e. the table initial data becomes criterion (a quantitative measure) identifications. For example, prime numbers and their ranks [15] have no measurement error: they are absolutely reliable, sound and reliable. Other types of basic data have a different error. Thus, mathematical numerical objects - the best for identification of laws invariants.

On the second place there are precision measurements in astronomy and physics [11] [12] [14] equipment and technology, other areas of science. On the third place there are biological objects, and their behavior has accurately being shown oscillatory character in adaptation to external influences therefore the linear and linearized models at all don't suit biologists. The highest errors have social and economic measurements because of their high subjectivity.

By us it was proved what exactly the analysis of the weak communications rejected at linear modeling, and application of arithmetic-mean factorial communication under Gauss-Laplace's law (normal distribution), gives new scientific ideas and the 
subsequent scientific and technical decisions (for 14 years with participation of students was taken out nearly 100 patents for inventions of the Russian Federation).

The literature analysis on mathematical statistics showed that in approximation the linear model or an algebraic polynomial not making physical sense is pretty often applied. It occurs because linear model invariant to any type of distribution and even to negative values of an explaining variable, including obviously non-Gaussian structure. Thus the linear model is applicable and to data of measurements with variable dispersion. It is applied by us at the beginning of procedures of statistical modeling, and then the model becomes complicated to the design containing the biotechnical law or its fragments.

Identification on a numerical field (tabular model) includes the following stages:

1) heuristic identification of an essence of the studied phenomenon or process by results of measurements and the analysis of tabular model (aprioristic information) and the subsequent judgment during design identification at statistical one-factorial regularity on its additive components (posteriori information);

2) structural identification of each one-factorial mathematical function in the general model as the sums of invariants in the form of asymmetric wavelet signals (we don't provide methodology of multiple-factor modeling in article);

3) parametrical identification increased on separate invariants of the structure each steady statistical regularity in the program environment CurveExpert-1.40 (http://www.curveexpert.net).

\section{Identification heuristic}

She assumes knowledge of an object of research therefore transition from physics to mathematics, and not the reverse here is important. The principal heuristic value gets the set numerical field, as a rule, made out by results of measurements or generalizing representations in the form of the table. In it all substantial sense (heuristics) and understanding (concept) of the author of measurements of deep sense of experiment is implicitly concluded.

The error of measurements by drawing up a numerical field, i.e. the table initial data becomes criterion (a quantitative measure) identifications. Thus this error is considered at a stop of the automated process of identification.

We refused long ago methods of approximation and, respectively, at all we don't apply the statistics program from the Excel environment.

In technology of identification the first stage (a variation of functions) is excluded from the theory of approximation, - steady laws are in advance set as invariants. From them as from bricks it is possible to create various mathematical constructs.

Use in each concrete example of statistical (probabilistic) modeling of this or that steady law (according to their table 1 of everything seven) demands preliminary heuristic judgment of the maintenance of a problem of modeling.

Thus, at the heuristic level the 23rd problem of Hilbert is still insufficiently formalized by us (because of an illegibility of the formulation of the problem). But it was completely solved at the structural and parametrical levels of the analysis and synthesis. The variation of functions is reduced to conscious selection of steady laws and designing on their basis adequate to the studied natural processes of steady wave 
regularities. Therefore the first stage is excluded from the existing theory of identification.

In the future the automated designing of one-factorial models for any tabular data (numerical matrixes) on multiple-factor measurements is supposed. It will repeatedly reduce labor input of statistical modeling. Thus the multiple-factor analysis of data is made by the binary relations on the sum wavelets.

\section{Identification structural}

Descartes assumed existence of the one and only algebraic equation suitable as the general version of the decision for any types of the integrated equations.

Hilbert dreamed of invariants from which as from bricks this universal equation will gather.

Our universal invariants are given in table 1. They are grouped in the principle "from simple to difficult" and complication of a form of steady laws in the form of the biotechnical law comes to the end with the generalized invariant.

In fact, fragments and the biotechnical law are "Hilbert's bricks" for construction, during process of structural and parametrical identification, an additive design of the required statistical determined or wave model.

Invariants of oscillatory indignations in the form of asymmetric wavelet signals also include constructs from table 1 as amplitude (half) and a half-cycle.

If are known heuristic background of formation of a numerical field (tabular model), semantic interpretation of each wavelet signal at which wavelet (wave function) in the design is quite possible contains these or those mathematical invariants from table 1.

\section{Table 1. Mathematical constructs (initial invariants) for drawing up statistical model}

\begin{tabular}{|c|c|}
\hline $\begin{array}{l}\text { Fragments without background of the } \\
\text { studied phenomenon or process }\end{array}$ & $\begin{array}{l}\text { Fragments with background of the } \\
\text { studied phenomenon or process }\end{array}$ \\
\hline $\begin{array}{l}y=a x \text { - the law of linear growth or } \\
\text { recession (at a negative sign before the } \\
\text { right side of a formula of linear change) }\end{array}$ & $\begin{array}{l}y=a-\text { the law not influences of the } \\
\text { accepted explaining variable on an } \\
\text { indicator which has own background of } \\
\text { values }\end{array}$ \\
\hline $\begin{array}{l}y=a x^{b}-\text { the law of indicative growth } \\
\text { (the law of indicative death } y=a x^{-b} \text { isn't } \\
\text { steady, because of infinity of an indicator } \\
\text { at zero value of an explaining variable) }\end{array}$ & $\begin{array}{l}y=a \exp ( \pm c x)-\text { Laplace's law in } \\
\text { mathematics (Zipf in biology, Pareto in } \\
\text { economy, Mandelbrot in physics) the } \\
\text { exponential growth or death concerning } \\
\text { which Laplace created methodology of } \\
\text { operator calculation }\end{array}$ \\
\hline $\begin{array}{l}y=a x^{b} \exp (-c x)-\text { the biotechnical law } \\
\text { in the simplified form (P. M. Mazurkin) } \\
\text { when indicative growth gradually receives } \\
\text { exponential braking }\end{array}$ & $\begin{array}{l}y=a \exp \left( \pm c x^{d}\right)-\text { the law of exponential } \\
\text { growth or death in a full form (design) } \\
\text { which has intensity of change of the } \\
\text { explaining variable, not equal to unit (P. } \\
\text { M. Mazurkin) }\end{array}$ \\
\hline \multicolumn{2}{|c|}{$\begin{array}{l}y=a x^{b} \exp \left(-c x^{d}\right) \text {-the biotechnical law, } \\
\text { the general for six constructs (P. M. Mazurkin) }\end{array}$} \\
\hline
\end{tabular}


All known laws of distribution are special cases of the biotechnical law that is shown in manuals and above in article.

Identification of structure of model is carried out by processing of basic data so:

- in the beginning it is necessary to reveal the determined nonlinear regularities;

- then to supplement these trend regularities with oscillatory indignations.

\section{Identification parametrical}

It is executed in a software environment CurveExpert-1.40 and our information identification technology used by students (future bachelors and masters), as well as graduate and doctoral students.

On many examples the methodology of structural and parametrical identification is in detail shown in [7] - [16].

The choice of structure of required model which is the algebraic decision on Descartes for an unknown antiderivative on the wave equations having variables amplitude and a half-cycle (frequency half as inverse value of a half-cycle) oscillatory indignation of object of research, that is his behavior in time, is carried out from the steady laws (invariants) provided in table 1.

Process of parametrical identification automatically stops on an achievement condition at parameters of model of some minimum increment and stops the user at achievement by designed statistical model of an error of measurements for the set numerical field.

Therefore the need for stages of building of required model new components depends on an error of measurements at experiments. In this regard the author of basic data always needs to estimate an error of measurements of own experiments.

Intervals of change of coefficient of correlation as measures of adequacy to the identified statistical model are given in table 2 .

Table 2. Levels of narrowness of factorial communications

\begin{tabular}{|c|c|c|c|c|}
\hline \multirow[b]{2}{*}{$\begin{array}{l}\text { Interval of } \\
\text { coefficient of } \\
\text { correlation }\end{array}$} & \multicolumn{4}{|c|}{ Nature of narrowness of communication between factors } \\
\hline & $\begin{array}{l}\text { the existing } \\
\text { classification }\end{array}$ & $\begin{array}{c}\text { scale for } \\
\text { technical } \\
\text { measurements }\end{array}$ & $\begin{array}{l}\text { scale for precision } \\
\text { measurements }\end{array}$ & $\begin{array}{l}\text { scale for genetic } \\
\text { engineering and ranks of } \\
\text { the whole prime numbers }\end{array}$ \\
\hline 1 & \multirow{6}{*}{$\begin{array}{l}\text { strong } \\
\text { communication }\end{array}$} & unambiguous & the unambiguous & the unambiguous \\
\hline $0.999 \ldots 1.0000$ & & \multirow{4}{*}{ the strongest } & the almost & the almost unambiguous \\
\hline $0,99 \ldots 1,000$ & & & unambiguous & the extremely strong \\
\hline $0,95 \ldots 0,99$ & & & the superstrong & the superstrong \\
\hline $0,90 \ldots 0,95$ & & & the strongest & the strongest \\
\hline $0,7 \ldots 0,9$ & & the strong & the strong & the strong \\
\hline $0,5 \ldots 0,7$ & \multirow{2}{*}{$\begin{array}{l}\text { weak } \\
\text { communication }\end{array}$} & average & average & average \\
\hline $0,3 \ldots 0,5$ & & rather weak & rather weak & rather weak \\
\hline $0,1 \ldots 0,3$ & \multirow{3}{*}{$\begin{array}{l}\text { there is no } \\
\text { communication }\end{array}$} & the weak & the weak & the weak \\
\hline $0,0 \ldots 0,1$ & & the weakest & the weakest & the weakest \\
\hline 0 & & $\begin{array}{l}\text { there is no } \\
\text { communication }\end{array}$ & $\begin{array}{l}\text { there is no } \\
\text { communication }\end{array}$ & $\begin{array}{l}\text { there is no } \\
\text { communication }\end{array}$ \\
\hline
\end{tabular}

The existing scale of quantification of narrowness of communication between the accepted factors (there is no communication, weak and strong communication) is very rough and even primitive. 
By us it is offered for technical experiments in which the error of measurements doesn't exceed 5\%, other scale (the third column of table 2). However it became clear that it is also not enough this scale of levels of adequacy.

\section{Asymmetric wavelet}

We adhere to Descartes's concept about need application of the algebraic equation of a general view directly as final mathematical solution of the unknown differential or integrated equations. For such generalization the new class of wave functions [7] [16] was offered.

To conditions of physical existence of the phenomena and processes asymmetric wavelet-function of a look most fully satisfies

$$
\begin{gathered}
y=\sum_{i=1}^{m} y_{i}, \\
y_{i}=a_{1 i} x^{a_{2 i}} \exp \left(-a_{3 i} x^{a_{4 i}}\right) \times \times \cos \left(\pi x /\left(a_{5 i}+a_{6 i} x^{a_{7 i}} \exp \left(-a_{8 i} x^{a_{9 i}}\right)-a_{10 i}\right),\right.
\end{gathered}
$$

where $y$ - an indicator (a dependent factor), $i$ - number of the making model (1), $m$ - number of members in model (1), $x$ - the explaining variable (the influencing factor), $a_{1} \ldots a_{10}-$ the parameters accepting numerical values during structural and parametrical identification in process of increase in coefficient of correlation in process of accumulation of quantity of components of statistical model (1).

In a formula (1) function of a cosine is a link between geometry and algebra and it contains two fundamental physical constants: $e$ (number of time or Napier's number) and $\pi$ (number of space or Archimedes's number). These constants give confidence of identification binding four types of interactions [7].

In most cases for identification of steady biotechnical regularities, because of rather low accuracy of tabular models, the truncated design (on the formula of the period enclosed in trigonometric function or fluctuation frequencies) asymmetric wavelet type is sufficient

$$
y=\sum_{i=1}^{m} y_{i}, \quad y_{i}=a_{1 i} x^{a_{2 i}} \exp \left(-a_{3 i} x^{a_{4 i}}\right) \cos \left(\pi x /\left(a_{5 i}+a_{6 i} x^{a_{7 i}}\right)-a_{8 i}\right) .
$$

The number $m$ of members in our examples up to 120 or more. For example, change of relative atomic mass of chemical elements depending on serial number in D. I. Mendeleev's table received model with 92 members [9].

\section{Dynamic range as a series of signals}

Physics and Mathematics approach involves understanding dynamic range as a reflection of some composite process or multiple series and parallel occurring natural and/or natural and anthropogenic real processes. For the first time it was succeeded to receive models of many types of series of dynamics on the concept of additive decomposition of any dynamic row on a set of signals.

The signal is a material data carrier. And information is understood by us as an interaction measure. The signal can be generated, but its reception isn't obligatory. So, for example, a number of prime numbers is known some thousands of years, but its essence as sets of signals still wasn't opened [7].

Any physical process or its part can be a signal. It turns out that change of a set of 
unknown signals is known long ago, for example, through ranks of hydrometeorological measurements in many points of a planet. However still there are no statistical models of dynamics of global temperature and other parameters of earth's environment.

Then we can write down any equation of type (2) as a look wavelet-signal

$$
y_{i}=A_{i} \cos \left(\pi x / p_{i}-a_{8 i}\right), A_{i}=a_{1 i} x^{a_{2 i}} \exp \left(-a_{3 i} x^{a_{4 i}}\right), p_{i}=a_{5 i}+a_{6 i} x^{a_{7 i}},
$$

where $A_{i}$-amplitude (half) of a wavelet (axis $y$ ),

$p_{i}$ - a half-cycle of fluctuation (axis $x$ ).

On a formula (3) with two fundamental physical constants $e$ (Napier's number or number of time) and $\pi$ (Archimedes's number or number of space) the quantized wavelet signal is formed from within the studied phenomenon and/or process.

The concept of a wavelet signal allows to abstract from physical sense of statistical ranks of measurements (generally not only dynamic ranks) and to consider their additive decomposition on separate components in a look wavelets.

\section{Asymmetric signals of the electrocardiogram}

The purpose - receiving mathematical model of a signal of the electrocardiogram [9]. One period of an electrocardiographic signal without pathology in a reference system is set $U(t)$, where: $t$ - time measured in milliseconds (ms); $U$ - heart tension in millivolts $(\mathrm{mV})$. The signal is given in figure 1.

The tabular model is presented usually in two forms - in the Excel program or a text editor of Word through coordinate points in the accepted reference system.

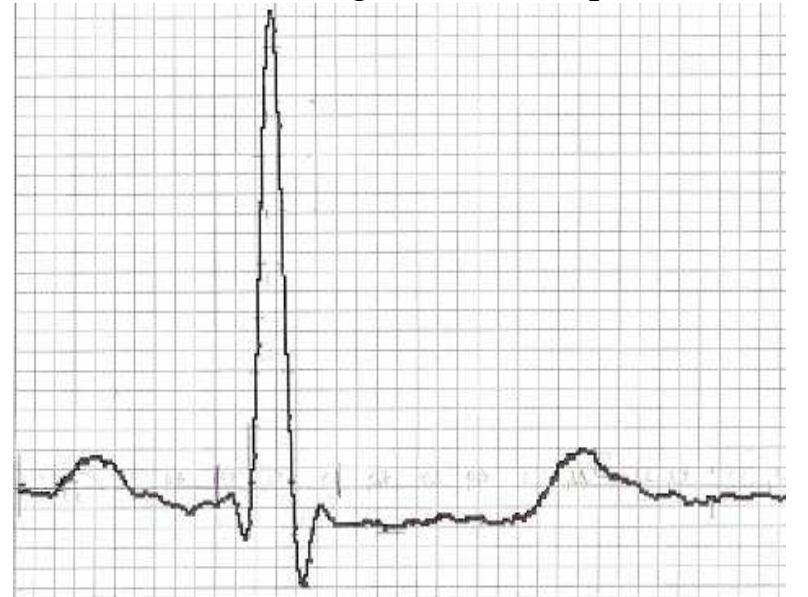

Figure 1. A grid for measurements of a signal of heart
In process of complication of a formula from the previous session of search more and more exact records of coefficients (model parameters) are accepted. Process comes to the end with the difficult nonlinear polynomial equation. The received equation will be mathematical model of this one signal of the electrocardiogram.

The schedule $U(t)$ of binomial model corresponding to the QRS complex of heart of the healthy person is given in figure 2.

On the remains from the model in figure 2 corresponding to a tooth of $\mathrm{T}$ of a signal of the electrocardiogram of heart of the healthy person it is shown in figure 3.

From the fifth component on the thirty third new asymmetric signals are received. But their accessory to fluctuations of cardiac muscles the implicit. Apparently, schedules of tension of electric signals can belong and to other human organs.

Parameters of model (1) and coefficient of correlation are specified in table 1. 


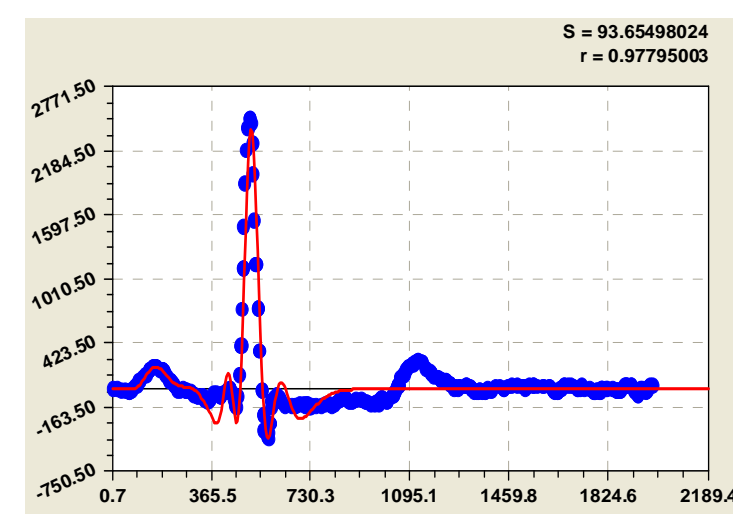

Figure 2. Work of an auricle and ventricle of heart

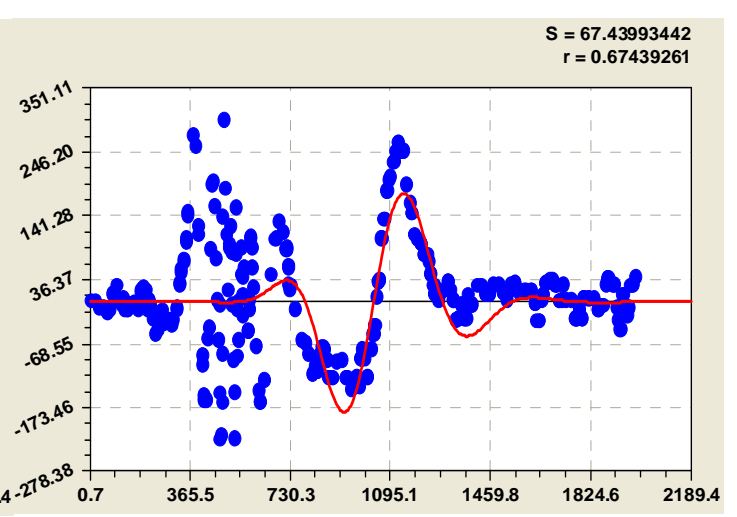

Figure 3. Work of an auricle after a heart ventricle

Table 3. Parameters of mathematical model of the electrocardiogram of heart without pathology

\begin{tabular}{|c|c|c|c|c|c|c|c|c|c|}
\hline \multirow{2}{*}{$i$} & \multicolumn{3}{|c|}{ Amplitude of fluctuation, $\mathrm{mV}$} & \multicolumn{3}{|c|}{ Half-cycle and shift of fluctuation, ms } & Correl. \\
\cline { 2 - 9 } & $a_{1 i}$ & $a_{2 i}$ & $a_{3 i}$ & $a_{4 i}$ & $a_{5 i}$ & $a_{6 i}$ & $a_{7 i}$ & $a_{8 i}$ & coef. \\
\hline 1 & $2.59574 \mathrm{e}-028$ & 16.74766 & 0.078955 & 1.04811 & 0 & 0 & 0 & 0 & \\
\hline 2 & $1.42992 \mathrm{e}-149$ & 63.76683 & 0.013904 & 1.30529 & 10.59449 & 0.0022405 & 1.344103 .18773 & 0.9780 \\
\hline 3 & $-3.40070 \mathrm{e}-033$ & 14.31631 & 0.000120 & 1.77400 & 21.15976 & 0.21683 & 0.87313 & 0.52152 & \\
\hline 4 & $-1.67937 \mathrm{e}-064$ & 25.57819 & 0.021603 & 1.01816 & 244.7042 & 0.0030608 & 0.98941 & 5.23804 & 0.6740 \\
\hline
\end{tabular}

The first three components give coefficient of correlation 0/9780. Therefore the equation (3) quite sufficient to facilitate to the cardiologist diagnostics of heart according to the digital electrocardiogram.

The signal of the electrocardiogram is measured in 0.001 seconds to $2200 \mathrm{~ms}$. Processing of signals in seismic exploration demands a time scale also in 0.001 seconds to $2500 \mathrm{~ms}$. In neurodynamics the time scale in 1 second till 1000 seconds is applied. In different examples of measurements and the wavelet analysis other units of time are applied.

\section{Dynamics of mass of moisture during natural drying of tests of a grass}

In the course of natural drying of the cut-off elevated part of a grass there are, at least, two processes: first, dehydration yet not of dead cellular structures from action of heat of air; secondly, moisture deduction by the deadened cages before evaporation of free moisture. In this example a unit of time is 1 hour to $2000 \mathrm{~h}$ [9].

Dynamics of mass of test No. 1 during natural drying of the cut-off test of a grass to ready hay on a trial platform is characterized by the equation (3) in a look

$$
\begin{gathered}
m_{t}=m_{t 1}+m_{t 2}+m_{t 3}+m_{t 4}, \\
m_{t 1}=248.199, m_{t 2}=656.388 \exp \left(-0.027137 t^{0.97918}\right), \\
m_{t 3}=A_{1} \cos \left(\pi t / p_{1}-0.23480\right), A_{1}=-26.05914 \exp (-0.0036376 t), \\
p_{1}=6.93112+0.00019461 t, m_{t 4}=A_{2} \cos \left(\pi t / p_{2}+2.38942\right), \\
A_{2}=7.05798 t^{0.55718} \exp (-0.029730 t), p_{1}=19.31141+0.032157 t
\end{gathered}
$$

In a formula (4) there are following symbols: $m_{t}$ - the mass of test of a grass in dynamics of natural drying, $\mathrm{g} / \mathrm{m}^{2}, m_{t 1}$ - mass of dry hay or grass of an air and dry 
state, $\mathrm{g} / \mathrm{m}^{2}, m_{t 2}$ - the mass of water in test of a grass in dynamics of its drying, $\mathrm{g} / \mathrm{m}^{2}$, $m_{t 3}$ - oscillatory indignation of cages of the cut-off grass, $\mathrm{g} / \mathrm{m}^{2}, m_{t 4}$ - oscillatory return of free water cages of a grass, $\mathrm{g} / \mathrm{m}^{2}, t$ - time of natural drying from the moment of cutting of test of a grass, $\mathrm{h}, m_{t b 0}=656,388$ - the mass of initial moisture in grass test, $\mathrm{g} / \mathrm{m}^{2}, A_{1}$ - amplitude (half) of indignation of cages of test of a grass, $\mathrm{g} / \mathrm{m}^{2}, A_{2}$ - amplitude (half) of indignation of the cages trying to reanimate circulation of moisture and to receive mineral substances, $\mathrm{g} / \mathrm{m}^{2}, p_{1}$ - the period (half) of indignation on moisture loss, $\mathrm{h}, p_{2}$ - the period (half) of indignation on recession of a metabolism, h.

The schedules constructed on a formula (4) are given in figure 4, and it has accurate physical interpretation of behavior of a grass after its cut.

The maximum relative error is equal $\left|\Delta_{\max }\right|=1.46 \%$. The increased waves are shown in figure 5. During the first $500 \mathrm{~h}$ natural drying in test of a grass there is a sharp fluctuation of dynamic weight $m_{t 4}$.

From schedules it is visible that the dynamic component $m_{t 4}$ quickly dies away in limits till 200 o'clock drying, and less dynamic component $m_{t 3}$ proceeds.

From four components on all 18 models type (3) criteria for an ecological and landscape assessment of a meadow are received: 1) rational time $t_{p}$ of natural drying of the cut-off grass to ready hay, h; 2) optimum time $t_{o p t}$ of drying, h; 3) maximum time $t_{\max }$ of drying of a grass, h; 4) air and dry mass of test of a grass $m_{1}=m_{c} \quad$ or hay, $\mathrm{g} / \mathrm{m}^{2} ; 5$ ) minimum mass of test $m_{\phi \min }, \mathrm{g} / \mathrm{m}^{2}$;

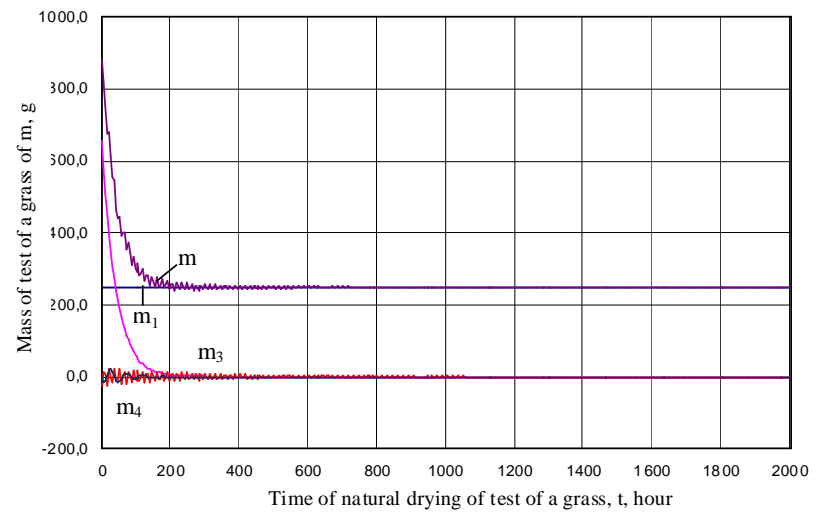

Figure 4. Dynamics of mass of a grass on a platform No. 1

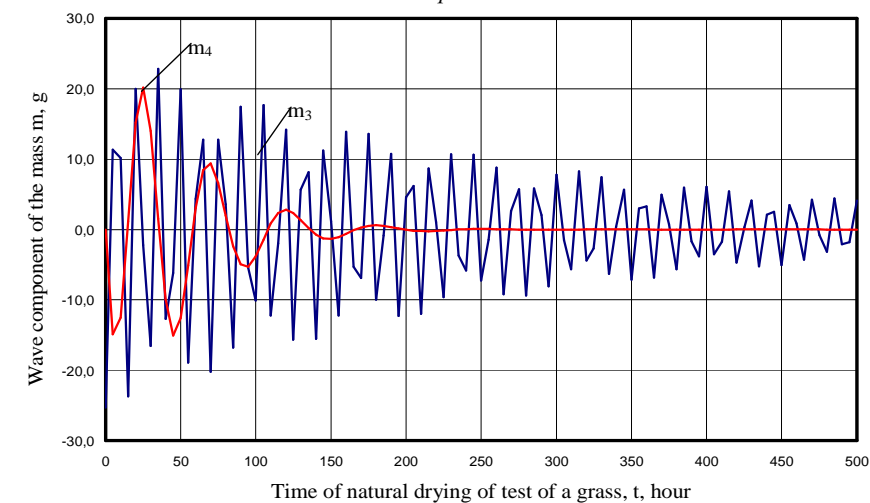

Figure 5. Wave components (4) to $500 \mathrm{~h}$

6) the maximum mass of a grass $m_{t=0}$ after a cut, $\left.\mathrm{g} / \mathrm{m}^{2} ; 7\right)$ the actual mass $m_{\phi 0}$ of test of the cut-off grass, $\mathrm{g} / \mathrm{m}^{2} ; \quad 8$ ) coefficient of dynamism of mass $k_{c}$ of the dried grass from humidity of air, as the relation of the third member (2) to the first; 9) coefficient of dynamism $k_{в л}$ of oscillatory return of moisture grass cages when drying; 10) the general coefficient of dynamism $k$ as the relation of the third with the fourth to the sum of the first and second members; 11) wave coefficient $k^{\text {cуики }}$ of dynamism of drying and moistening (the sum of the third and fourth 
components to the first); 12) humidity of test, \%: a) $W_{t}$ in a statics (the second part to the first); b) $W_{t}^{\partial u t}$ in dynamics (the sum of the second, third and fourth parts to the first).

Further we will show the analysis of the land registry of the Kirov region in time cut (year) on mutual influence of the wood (a biosphere kernel) and arable lands (an agriculture kernel).

\section{Influence of plowing on woodiness of the territory}

The model of influence $\varsigma$ of plowing $\xi$ on woodiness was executed in the program environment CurveExpert-1.38 [9].

On all 39 points (fig. 6a) the trend as the law of exponential death is received

$$
\xi=89.423 \exp \left(-0.020159 \varsigma^{1.03112}\right) .
$$

After identification (3) dependence with two waves was received (fig. 6b):

$$
\begin{gathered}
\xi=88.1519 \exp \left(-0.015018 \varsigma^{1.09609}\right)- \\
A_{1} \cos \left(\pi \varsigma / p_{1}+3.73625\right)-A_{2} \cos \left(\pi \varsigma / p_{2}-2.93701\right)
\end{gathered}
$$

$A_{1}=1.6271 \cdot 10^{-11} \varsigma^{11.66004} \exp \left(-0.37494 \varsigma^{1.03215}\right), p_{1}=0.98432-0.00022766 \varsigma^{1.29696}$,

$A_{2}=1.9405 \cdot 10^{-6} \varsigma^{4.86423} \exp \left(-0.073799 \varsigma^{1.06910}\right), p_{2}=1.17786+2.5262 \cdot 10^{-5} \varsigma^{1.36585}$.

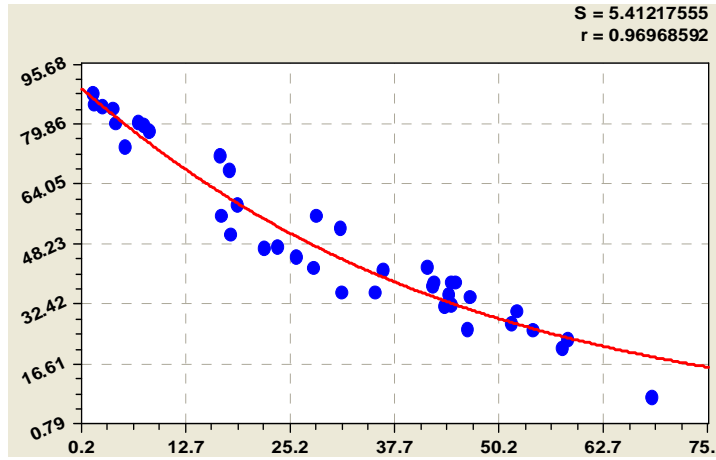

a) regularity trend

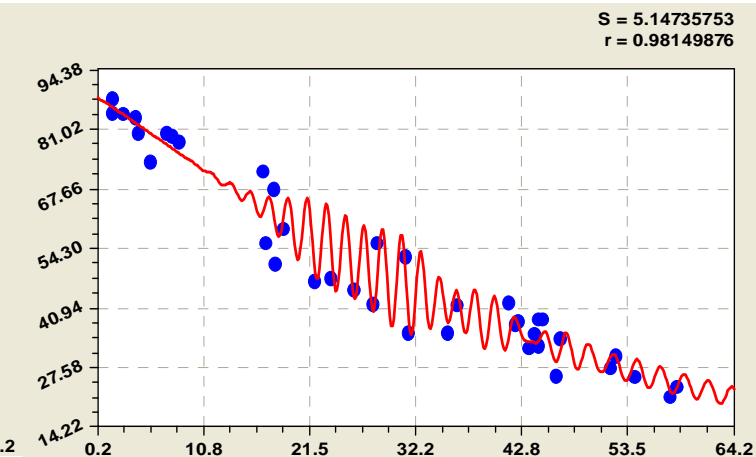

b) trend and accounting of two waves

Figure 6. Change of woodiness of from plowing of the territory of rural regions of the Kirov region (Russia)

Both fluctuations have a negative sign, therefore indignations crisis. In figure $6 \mathrm{~b}$ three clusters of municipalities having different style of behavior are visible.

The trend received (fig. 7a) a formula



a) regularity trend
(7) $S=3.96752864$ $r=0.98635562$

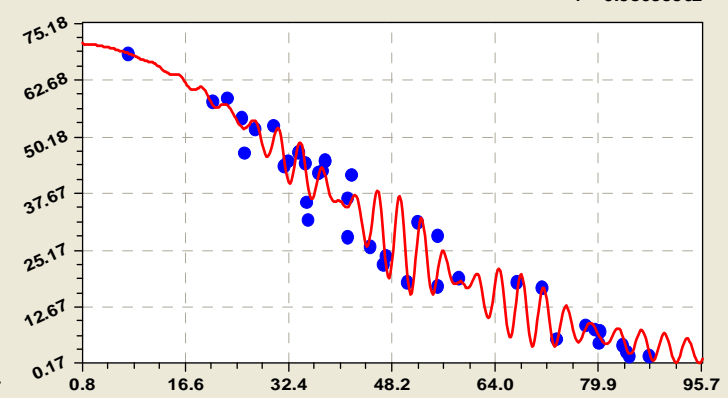

b) trend and accounting of two waves

Figure 7. Changing plowing from woodiness of the territory the Kirov region 
Connectivity $\varsigma=f(\xi)$ is better in comparison with structure $\xi=f(\varsigma)$. Thus, at the heart of relationship with the earth nevertheless the ancient tradition of fire agriculture which nowadays and developments is in the heat of growth in the territory of the Amazon River remained.

After identification of a trend and two wavelets of crisis oscillatory indignation of rural regions of the Kirov region the look formula was received (fig. 7b)

$$
\begin{gathered}
\varsigma=70.6987 \exp \left(-0.00069398 \xi^{1.85728}\right)- \\
A_{1} \cos \left(\pi \xi / p_{1}+1.92141\right)-A_{2} \cos \left(\pi \xi / p_{2}-3.46367\right), \\
A_{1}=5.5756 \cdot 10^{-10} \xi^{7.15573} \exp \left(-0.025332 \xi^{1.35448}\right), p_{1}=1.48498+0.0024279 \xi^{0.70307}, \\
A_{2}=1.8184 \cdot 10^{-5} \xi^{4.22294} \exp \left(-0.077257 \xi^{1.00723}\right), p_{2}=1.91267-0.00029107 \xi^{1.12624} .
\end{gathered}
$$

In total six more wavelet functions from which four are adaptation indignations (a positive sign ahead of a component), and two - crisis fluctuations were found. Thus, the total of crisis indignations is also equal to four. In total in statistical model nine members are formed.

The first adaptation happened (fig. 8a) on a formula

$$
\begin{gathered}
\varsigma_{4}=A_{3} \cos \left(\pi \xi / p_{3}-2.35408\right), \\
A_{3}=0.0010605 \xi^{3.43357} \exp \left(-0.10955 \xi^{1.01955}\right), p_{3}=1.67066+0.0092795 \xi^{1.00397} .
\end{gathered}
$$

The second adaptation (fig. $8 \mathrm{~b}$ ) happened on dependence

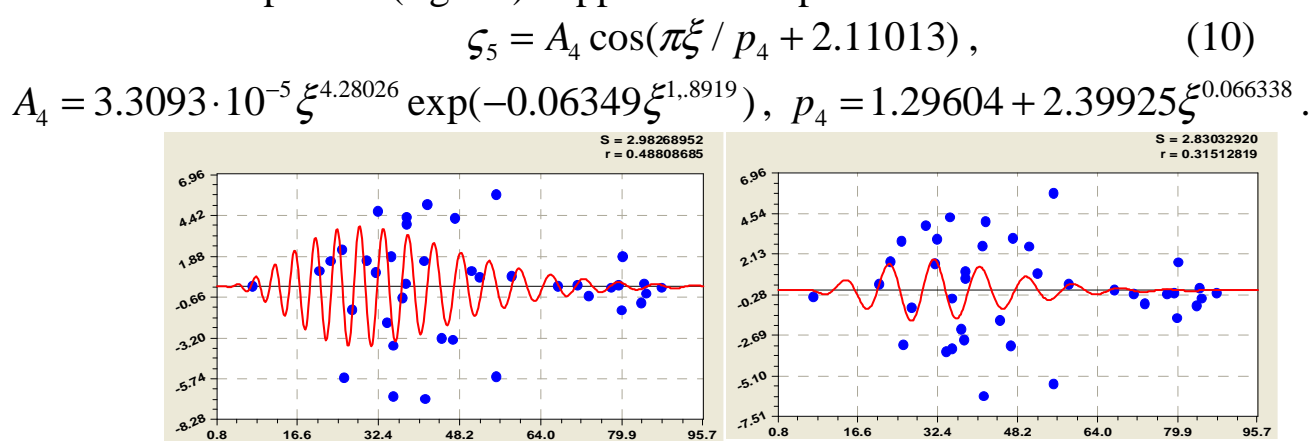

a) first adaptation of plowing

b) second adaptation of plowing



c) third adaptation of plowing
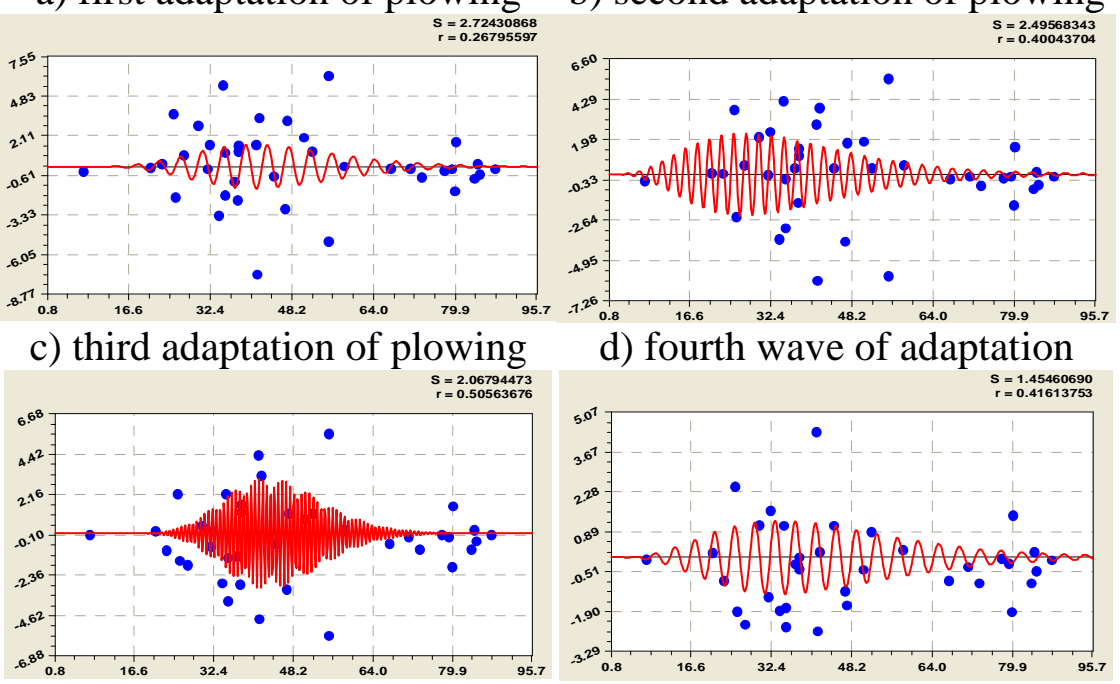

d) fourth wave of adaptation

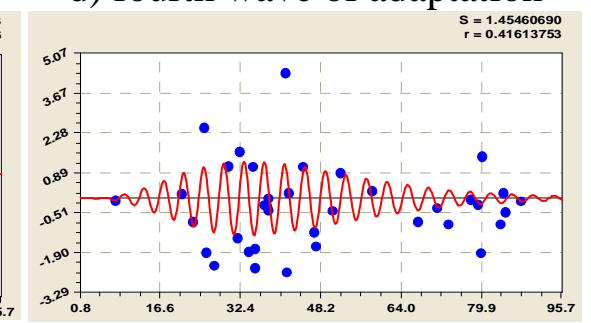

e) crisis on the seventh wave

f) crisis on the eighth wave

Figure 8. Additional to the model (6) adaptation and crisis wave

The adaptation of waves goes from left to right, reducing values of the remains of an indicator of plowing of the territory. Thus it is noticeable that rural areas with the 
high level of woodiness don't react to an indicator of plowing as in their territories the forest industry is developed.

The third adaptation (fig. 8c) happened on expression

$$
\begin{gathered}
\varsigma_{6}=A_{5} \cos \left(\pi \xi / p_{5}-1.71299\right), \\
A_{5}=1.0430 \cdot 10^{-10} \xi^{8.30052} \exp \left(-0.11773 \xi^{1.11605}\right), p_{5}=2.13681-0.0017717 \xi^{0.72567} .
\end{gathered}
$$

The fourth adaptation took place (fig. 8d) on the wave equation

$$
\begin{gathered}
\varsigma_{7}=A_{6} \cos \left(\pi \xi / p_{6}-0.054939\right), \\
A_{6}=0.00031957 \xi^{4.32976} \exp \left(-0.38203 \xi^{0.80143}\right), p_{6}=1.08772+0.0010660 \xi^{1.19734} .
\end{gathered}
$$

The third crisis wave taking into account the first, earlier found two wave working out the equations (8) in figure $8 \mathrm{e}$ the crisis equation is shown

$$
\begin{gathered}
\varsigma_{8}=-A_{7} \cos \left(\pi \xi / p_{7}-6.14360\right), \\
A_{7}=1.9079 \cdot 10^{-22} \xi^{17.9898} \exp \left(-0.27366 \xi^{1.09016}\right), p_{7}=0.38620 .
\end{gathered}
$$

The eighth component receives the constant frequency of fluctuation.

It appeared that Verhoshizhemsky and Sloboda rural areas have equal woodiness of $55.4 \%$. However at them, respectively, plowing of the territory is equal 28.4 and $17.1 \%$. This difference in $28.4-17.1=11.3 \%$ is also shown by the program CurveExpert-1.38.

The fourth crisis wave turned out after an exception of these two rural areas (fig. 8f) in the form of model of crisis indignation of a look

$$
\begin{gathered}
\varsigma_{9}=-A_{8} \cos \left(\pi \xi / p_{8}+0.33343\right), \\
A_{8}=5.0120 \cdot 10^{-5} \xi^{4.16535} \exp \left(-0.17636 \xi^{0.92042}\right), p_{8}=1.89268+0.0079272 \xi^{0.58743} .
\end{gathered}
$$

On character of an arrangement of the remains it was visible that also the subsequent wave components of model are possible. However the maximum relative error already came nearer to an error of measurements of the area of the territory. Therefore there is no need for further building of a design of the general statistical regularity. It is clear, that in the Kirov region woodiness parameter still influences change of coefficient of a plowing of the territory.

\section{Analysis of fractal representation of wavelet sums}

A ring width analysis was conducted on cores of 7 oaks (Querqus robur L.) growing near the town of Zelenodolsk in the Republic of Tatarstan [16]. Mathematical models of the ring width and its dynamic patterns have been presented for tree \# 5. The models described consist of more than 100 asymmetric wavelet signals. This enables to draw heuristic identification of causes for every wave of the oak radial-growth. The matrix of the model parameters is given, and comparison of oaks on biological timing and graphical representation of relationships is carried out. The forecast of the ring width for tree \# 5 is given up to 2050 .

Different shaped signals are self-similar, i.e, fractal in their repeating pattern. Mandelbrot law shows that fractals are similar $y=a_{1} \exp \left(-a_{2} x\right)$. For the fractal model of a wavelet sum the maximum absolute error (residue) $\left|\varepsilon_{\max }\right|$ has become a typical characteristic parameter. 
Using the data [16], we get the following formula (fig. 9):

$$
\begin{array}{r}
\quad\left|\varepsilon_{\max }\right|=1829.860 \exp \left(-0.15483 i^{0.70934}\right)+A \cos (\pi i / p-0.66347), \\
A=58.40831 i^{0.86288} \exp (-0.11493 i), p=0.87957+0.017078 i^{1,57394} .
\end{array}
$$

Thus, asymmetrical wavelet (3) provides an opportunity to numerically describe the previously unknown processes and behavior of oak \# 5 with a high degree of adequacy, having adopted the correlation coefficient of 0.9975 .

For heuristic identification of the past behavior, the results of phenomenological observations are necessary [16].

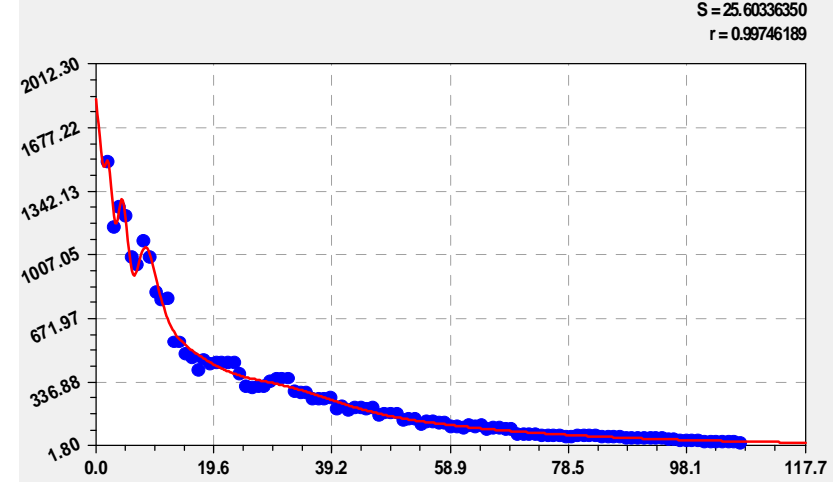

Figure 9. Diagram of fractal changes absolute error depending on the component number

\section{Crisis dynamics of ruble exchange rate}

Table 5. Tabular model of dynamics of ruble exchange rate to dollar from 06.01 .1993 for 31.12.2004.

\begin{tabular}{|c|c|c|}
\hline Date & $t$, day & $K, \mathrm{rub} / \$$ \\
\hline 22.01 .1993 & 22 & 493.0000 \\
\hline 20.01 .1993 & 20 & 474.5000 \\
\hline 15.01 .1993 & 15 & 442.0000 \\
\hline 13.01 .1993 & 13 & 423.0000 \\
\hline 06.01 .1993 & 6 & 417.0000 \\
\hline$\ldots$ & $\ldots$ & $\ldots$ \\
\hline 12.01 .2004 & 4070 & 28.9918 \\
\hline 09.01 .2004 & 4067 & 29.1350 \\
\hline 08.01 .2004 & 4066 & 29.2450 \\
\hline 06.01 .2004 & 4064 & 29.4545 \\
\hline 05.01 .2004 & 4063 & 29.4545 \\
\hline
\end{tabular}

The fragment of tabular model for an identification of function of type $K=f(t)$ is given in table 5 (on days from 06.01.1993 till 31.12.2004 only 2522 supervision) [13]. For 06.01.1993 value of the explaining variable $t=0$.

The main model of crisis of ruble is received by computing opportunities of the program environment CurveExpert-1.40 in the form of a formula

$$
K=K_{1}+K_{2}+K_{3}+K_{4}+K_{5},
$$

$$
K_{1}=1596.1347 \exp (-0.0028496 t) \text {, }
$$

$K_{2}=1.26648 \cdot 10^{-16} t^{7.47867} \exp \left(-0.0031169 t^{1.10028}\right)$,

$K_{3}=A_{1} \cos \left(\pi t / p_{1}-2.55294\right)$,

$$
A_{1}=-5.52024 \cdot 10^{-23} t^{9.43835} \exp \left(-0.0036385 t^{1.07839}\right) \text {, }
$$

$p_{1}=288.21469+758.00773 t^{0.020296} \exp \left(-0.00020804 t^{1.08303}\right)$,

$K_{4}=A_{2} \cos \left(\pi t / p_{2}+3.09398\right)$,

$A_{2}=-1.50797 \cdot 10^{6}(t-1826.3984)^{-1} \exp \left(-0.00031963 t^{1.23941}\right)$,

$p_{2}=371.72980, K_{5}=A_{3} \cos \left(\pi t / p_{3}+0.20634\right)$,

$A_{3}=23035.3488(t-1825.8462)^{-1}, p_{3}=22.28533$.

Each component (16) makes physical (economic) sense.

The first component under the law of exponential death (Pareto's law in economy, Zipf in biology, Mandelbrot in physics and Laplace in mathematics) shows natural aspiration of the Russian economic system to decrease by 06.01 .1993 in the gathered course of domestic currency $K_{0}=417 \mathrm{rub} / \$$.

The second component under the biotechnical law shows stressful excitement of the Russian financial system. 
Together two components give a trend in the form of not the wave (determined) binomial formula (fig. 10).

Other three members are wave functions which define computing approaches of quantum informatics in some sense. But, despite a rupture of the actual ruble exchange rate because of denomination by 1000 times, us it was proved that is possible to describe a default smooth functions. Thereby once again is confirmed that social and economic crisis of any power can be described statistical models on good

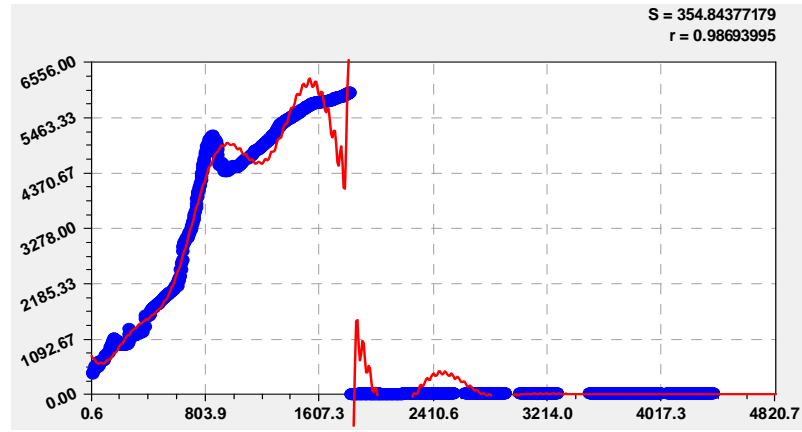

Figure 10. The schedule of statistical model (16) of dynamics of ruble exchange rate during the crisis period quality selections.

The third component in the form of mega fluctuation is the main, showing chaotic while clearly unwitting economic management. This oscillatory indignation nearly brought to collapse and is similar to behavior of obviously upset natural biological systems.

The fourth and fifth components show a ruble default. This process of a default us is described by a type hyperbole (fig. 11)

$$
y=k / x, k=-a \exp \left(-b t^{c}\right) \cos (\pi t / d+e), x=t-1826.3984,
$$

where $a, b, c, d, e$ - the parameters of model (17) identified in the program environment.



trend from two members first indignation $\mathrm{S}=562.49913541$

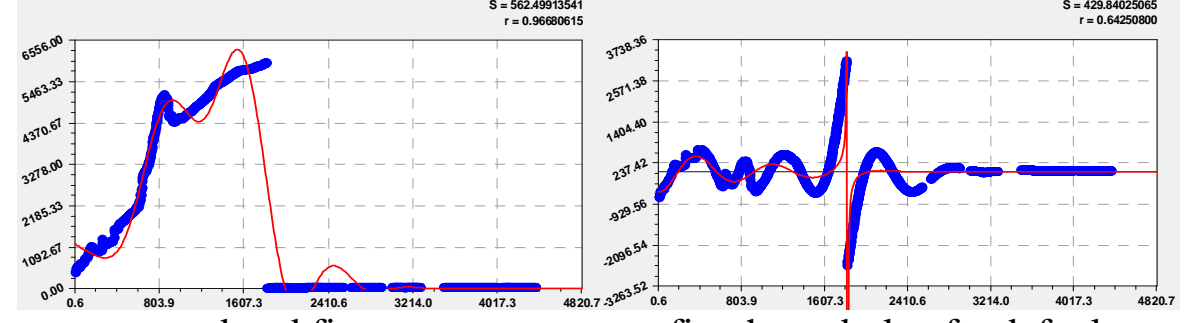

trend and first wave

first hyperbole of a default

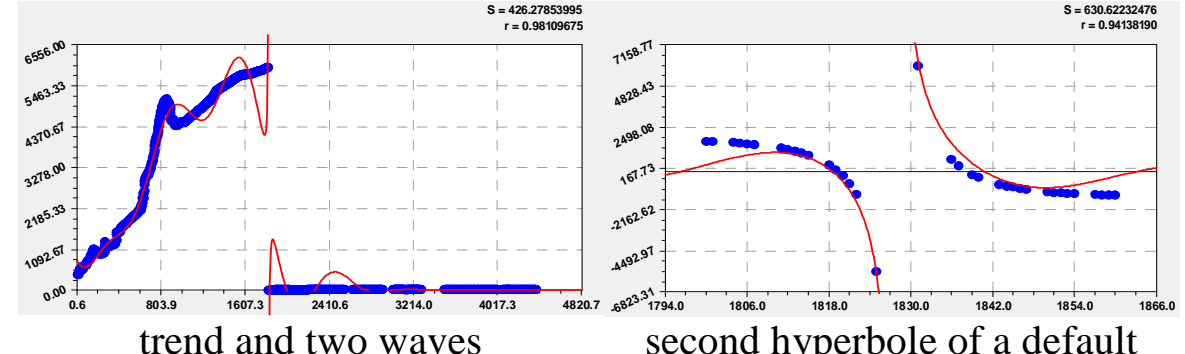

Figure 11. Schedules of separate components of model (16) 
In figure 11 the third wave of hyperbolic fluctuation is shown for the points which are near date of a default and it is characterized by a formula (17) with model parameters:

$a=23035.3488 \mathrm{rub} / \$, b=0, c=0, d=p_{3}=22.28533$ day, $e=1825.8462$ days.

From a formula (16) it is visible that there were two defaults. If not urgent measures of financial stabilization, on elements of the third member ruble exchange rate would reach the level of $1.5079710^{6} \mathrm{rub} / \$$ in the beginning, and then $23035.35 \mathrm{rub} / \$$. On 06.01.1993 the periods are equal: $2 p_{1}=2 \times 288.21462 \approx 576.4 ; 2 p_{2}=743.5 ; 2 p_{3}=$ 44.6 days.

\section{Patenting volume in Russia}

The number of patents for intellectual property in our country changes [9] according to schedules in figure 12 on a formula

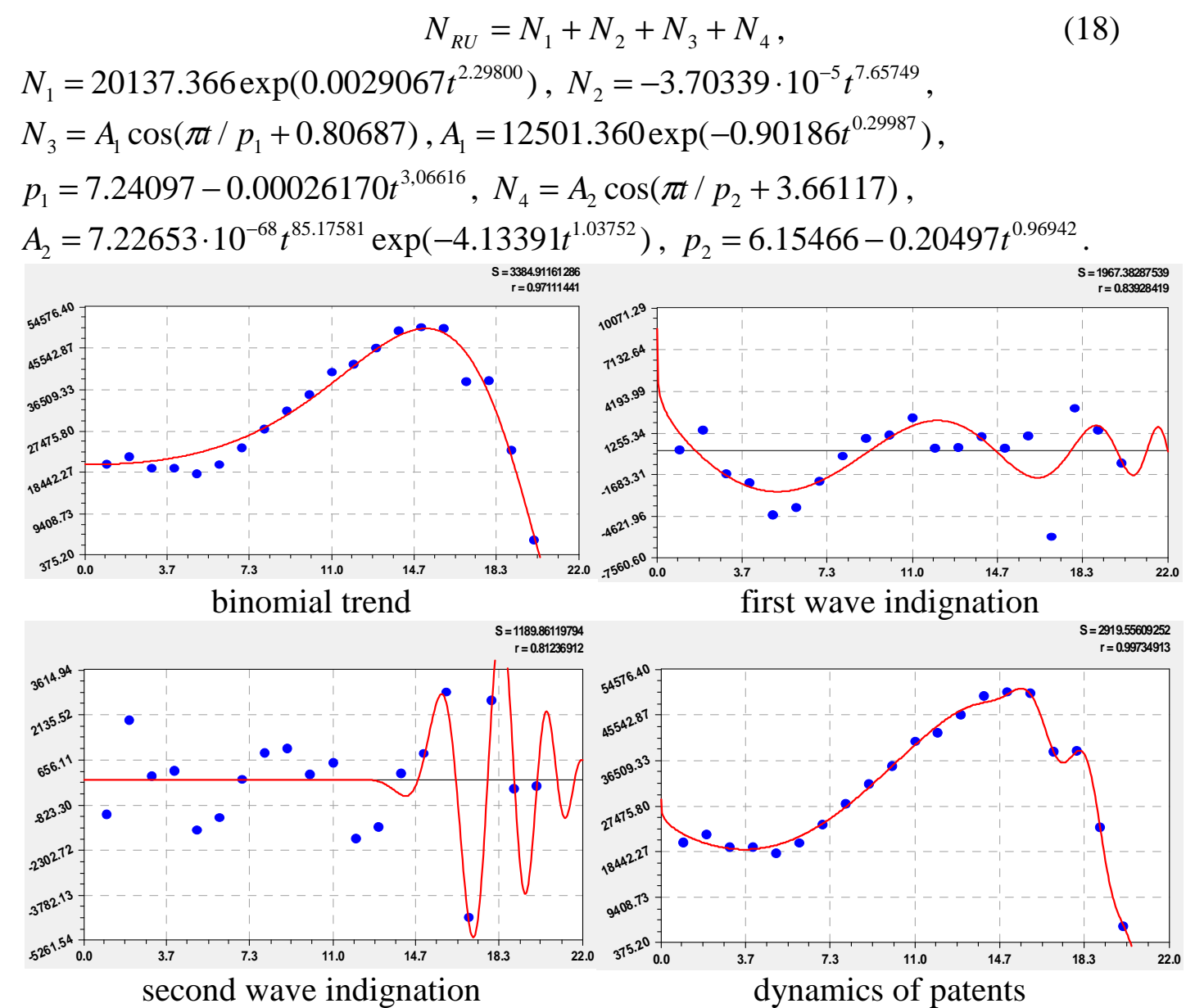

Figure 12. Dynamics of number of patents in Russia in 1992-2012

The first component (18) is the law of exponential growth in a full form. It is natural part of a trend. And the second component shows crisis (a negative sign before the member) change of number of the Russian patents. As a result of binomial trend in figure 1 receives a tendency of some increase from 1998 to 2007. But after 2007 the second component starts exceeding sharply the natural first member of the equation (18). Understanding of the strongest crisis in innovative development of the country in the second member of the equation (18) would allow to take effective measures and to reduce rates of recession of volume of patenting. 


\section{Dynamic number of forest fires as series of signals}

As an example in figure 13 schedules of the physical and mathematical analysis of dynamics of forest fires for 1982-2011 in «Mary Chodra» on several wavelets are shown (models aren't given).
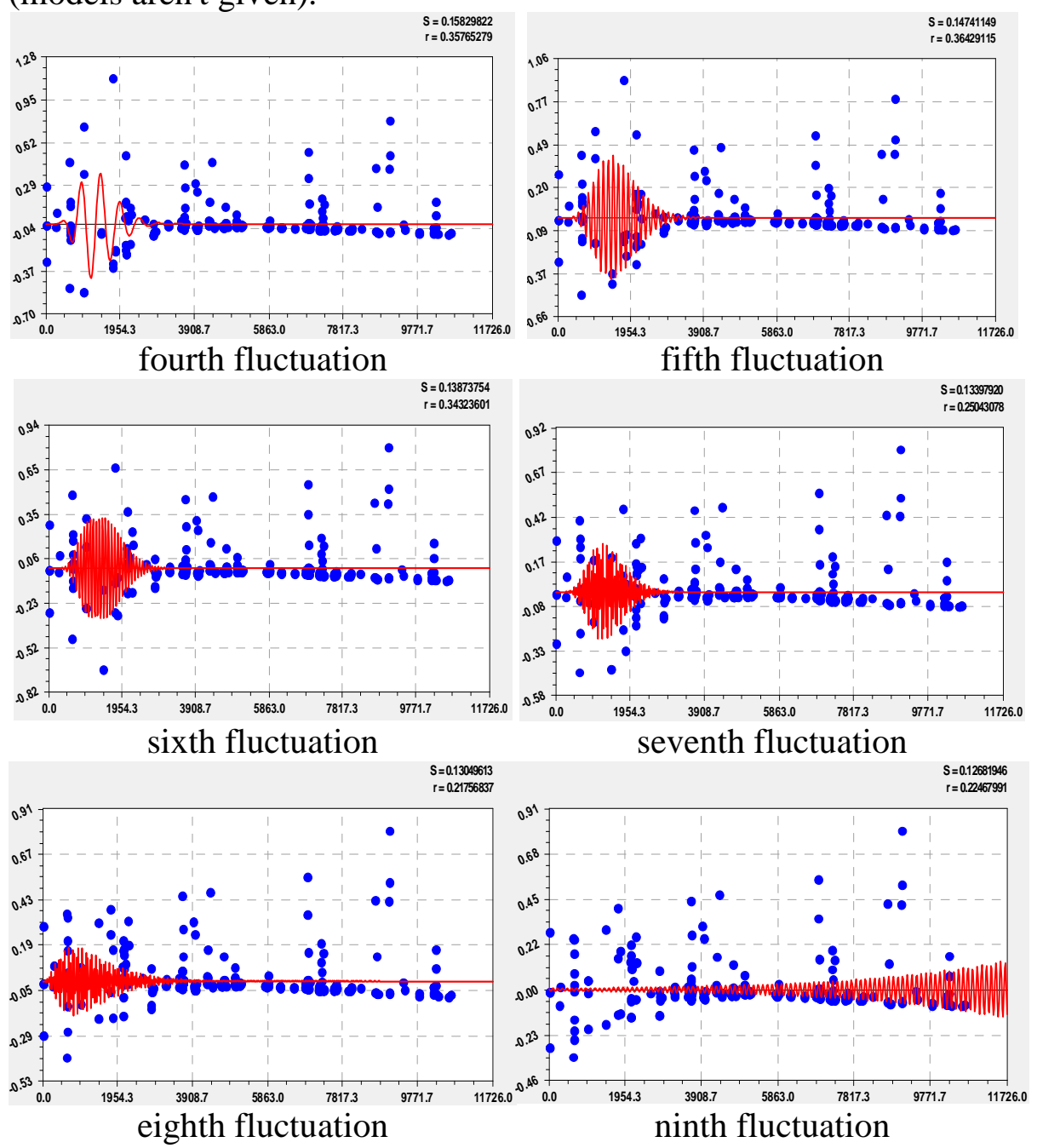

Figure 13. Schedules of separate asymmetric wavelet signals

from the general statistical model of dynamics of the area of forest fires from measurement time in days during 1982-2011

And on the revealed regularities it would be possible to execute the indicative inertial forecast for the forecast horizon equal to the forecast basis (to a period from zero before the last measurement of forest fire), and also the working inertial forecast for one third of the period of last measurements of forest fires. As a result efficiency of suppression of the fires increases. Application of the offered method expands possibilities of territorial environmental monitoring.

\section{Inflation of US dollar}

The current annual rate of inflation on months since $01.2000\left(i_{m}=1\right)$ till 05.2015 $\left(i_{M}=185\right)$ gave a trend (fig. 14) on a formula

$$
k=3.39051 \exp \left(-0.00010189 i_{M}^{1.75733}\right),
$$

where $k$ - current monthly index of inflation, \%,

$i_{M}$ - number of month about reference marks (January 2000). 
In the table 6 parameters of model (3) are given in compact record in a matrix form with rounding to the 5 th significant figure.

Table 6. Parameters of model (3) on dynamics of inflation of US dollar

\begin{tabular}{|c|c|c|c|c|c|c|c|c|c|}
\hline \multirow{3}{*}{$\begin{array}{c}\text { Num } \\
\text { ber } \\
i\end{array}$} & \multicolumn{8}{|c|}{ Asymmetric wavelet $y_{i}=a_{1 i} x^{a_{2 i}} \exp \left(-a_{3 i} x^{a_{4 i}}\right) \cos \left(\pi x /\left(a_{5 i}+a_{6 i} x^{a_{7 i}}\right)-a_{8 i}\right)$} & \multirow{3}{*}{$\begin{array}{c}\text { Correl. } \\
\text { coeff. } \\
r\end{array}$} \\
\hline & \multicolumn{4}{|c|}{ amplitude (half) of fluctuation } & \multicolumn{3}{|c|}{ fluctuation half-cycle } & \multirow{2}{*}{\begin{tabular}{|c|} 
shift \\
$a_{8 i}$ \\
\end{tabular}} & \\
\hline & $a_{1 i}$ & $a_{2 i}$ & $a_{3 i}$ & $a_{4 i}$ & $a_{5 i}$ & $a_{6 i}$ & $a_{7 i}$ & & \\
\hline 1 & $201+3$ & 0 & 00101 & 91.75733 & 0 & 0 & S & 0 & \multirow{3}{*}{0.8249} \\
\hline 2 & .15 & & & & 807 & 15201 & \multicolumn{2}{|c|}{1.084702 .06694} & \\
\hline 3 & & & 0.0 & \multicolumn{5}{|c|}{0.9977948 .09030} & \\
\hline 4 & 1.95 & & 0.00 & & 7160 & & \multirow{2}{*}{\multicolumn{2}{|c|}{$\begin{array}{ll}0.522440 .88910+ \\
1.060994 .26892\end{array}$}} & \\
\hline 5 & & & & & & & & & \\
\hline 6 & -4.2. & 4.0 & 0.13670 & 0.99543 & 316.78556 & -0.0 & \multicolumn{2}{|c|}{$1.00620-0.26446$} & \\
\hline 7 & & 535 & $\mathbf{0}$ & $\mathbf{0}$ & 59.13445 & -0.20446 & \multicolumn{2}{|c|}{$0.99997-1.86825$} & 0.6 \\
\hline 8 & & 0 & 0.0014095 & 1 & 2.62174 & -0.00 & \multicolumn{2}{|c|}{ 61.08161-4.02423 } & 0. \\
\hline 9 & -1.69 & 12.30873 & 0.091973 & 2876 & 8.13379 & -0.012445 & \multicolumn{2}{|c|}{$0.98806-2.02581$} & 0. \\
\hline 10 & & 0 & & 1 & 0 & 0 & 0 & 0 & 357 \\
\hline 11 & 3.710 & 21.34343 & 0.32179 & 0.99433 & 333.13995 & -0.17725 & \multicolumn{2}{|c|}{$0.99803-1.85391$} & \\
\hline 12 & .66 & 20.41071 & 0.22712 & 0.996 & 91.82 & 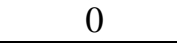 & 0 & 5.62821 & \\
\hline 13 & -0.14725 & 0.20865 & 0.00 & 51.99 & & 0 & 0 & -4.47439 & \\
\hline 14 & 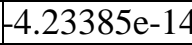 & & & & & 0.00 & 130. & 2.72632 & 0.1424 \\
\hline
\end{tabular}

Note. Dangerous fluctuation is highlighted in bold type.

In table 6 it is allocated dangerous for future fluctuation with an amplitude increasing under the indicative law. Thus at many fluctuations the half-cycle decreases (a negative sign before parameter $a_{6 i}$ ). The component 10 at model (3) shows that till 2000 there was an indignation which then passed under the law of death for 20002015. After the 14th member statistical modeling is complicated because of emergence of noise in data. Besides, also the adequacy indicator decreases to 0.1424.

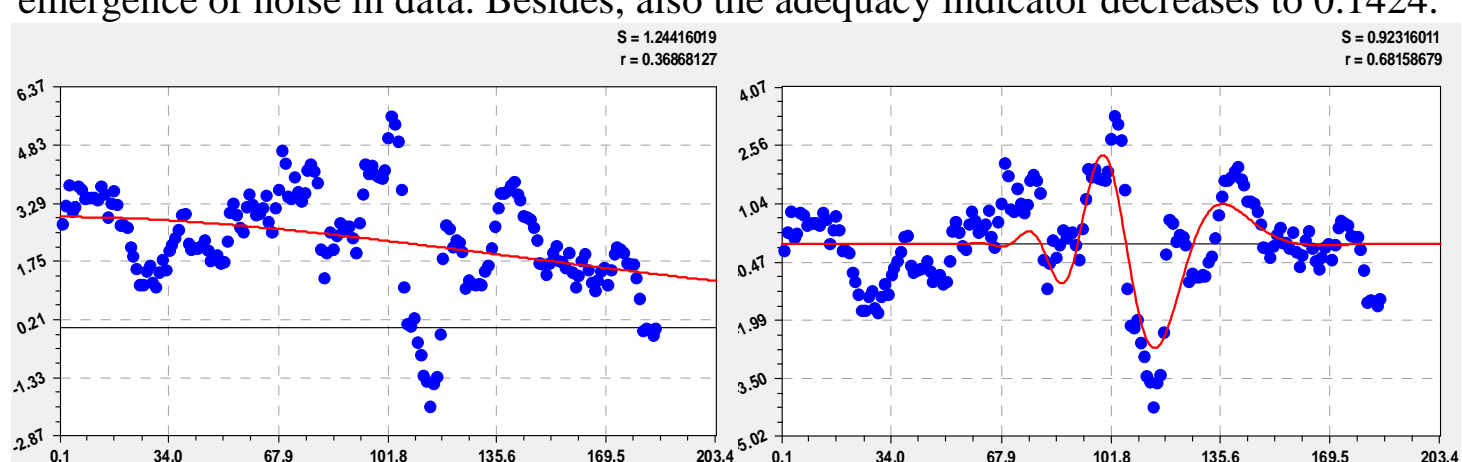

Trend under the law of exponential death

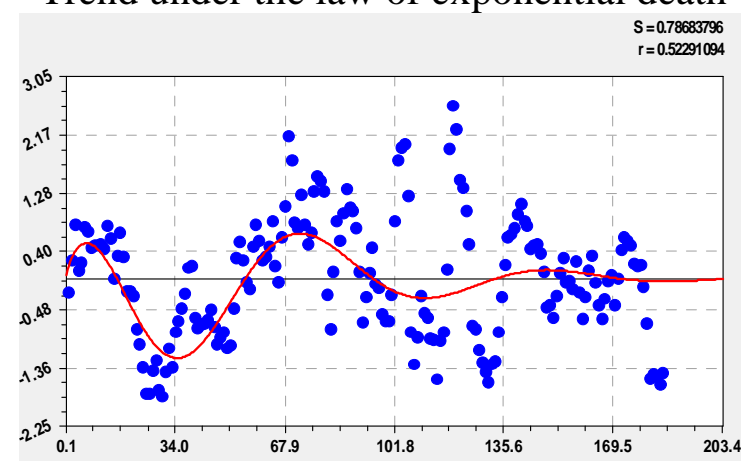

Second oscillatory indignation
First oscillatory indignation

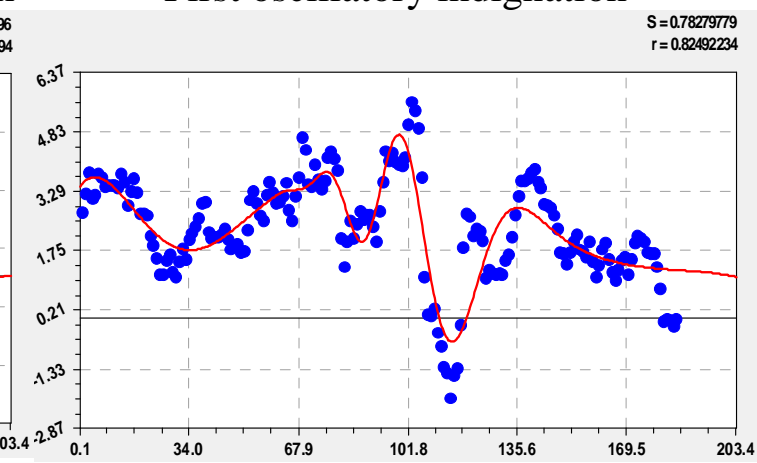

Trend and two fluctuations of inflation

Figure 14. Mega fluctuations of wave adaptation of dollar USA 01.2000-05.2015 
If to take a dynamic row till 2000 (since 1961 or even since 1900), it appears that the trend turns into a mega fluctuation with a long period compared to those in table 6 , the period of the second fluctuation $2 \times 48.09030 \approx 96.2$ months or eight years.

From the schedule it is visible that negative inflation in the USA already was at an abscissa $i_{M}=112 \ldots 118$ with a maximum of $-2.10 \%$ in July, 2009. The second time such phenomenon is observed since 01.2015, a maximum of $-0.20 \%$ in April, 2015.

\section{Model of the lapping Universe}

From schedules in figure 15 it is visible that gravitational oscillatory indignation of star systems on amplitude $h$ happens in the range of a cycle time of pulsars 0.1-1.0 days.
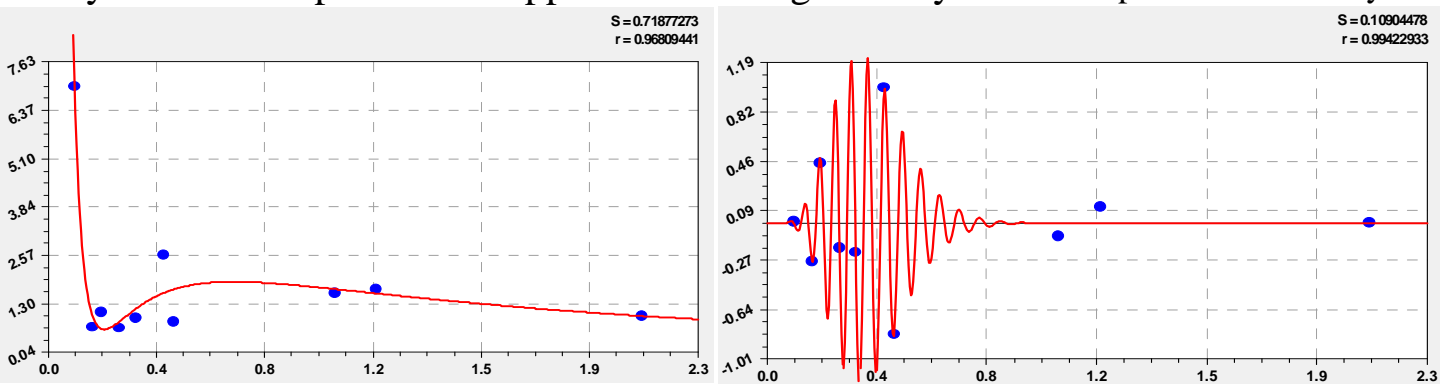

binomial trend wavelet signal from 10 pulsars
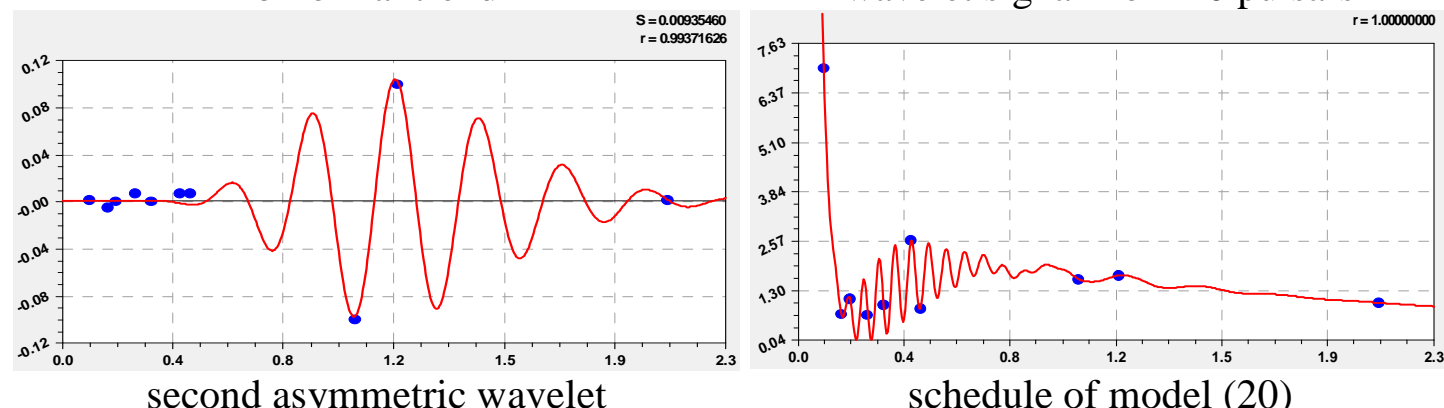

Figure 15. The schedule of statistical model (20) of change of amplitude of gravitational waves

In this interval there are seven star systems, except three pulsars of PSR J0700+6418, PSR J1829+2456 and PSR J1439-5501. They are located to the right of a pointer point 1,0 [14]. The interval of a cycle time of pulsars in the second fluctuation changes from 0.4 to 2.2-2.3 days. Two fluctuations are in the range of 0.4-1.0 days.

All four members give model of the lapping Universe (fig. 15) of a look

$$
\begin{aligned}
& 10^{22} h_{0}=h_{01}-h_{02}-h_{03}+h_{04}, \\
& h_{01}=10045843.0 \exp \left(-13.119916 T^{0.12626636}\right), \\
& h_{02}=756195.75 \exp \left(-10.623253 T^{0.16669093}\right), \\
& h_{03}=A_{1} \cos \left(\pi T / p_{1}-1.9456439\right), A_{1}=8808164.2 T^{6.9036732} \exp \left(-20.080126 T^{0.7992200}\right), \\
& p_{1}=0.024095462+0.0073109174 T^{1.0864200}, h_{04}=A_{2} \cos \left(\pi T / p_{2}-3.2854931\right), \\
& A_{2}=2631.0001 T^{9.3234819} \exp (-9.7213955 T), \\
& p_{2}=0.13093392+0.0014765024 T^{2.122200} .
\end{aligned}
$$

From a formula (20) it is visible that the periods of fluctuations of amplitude of gravitational waves under a condition $T=0$ are equal at the first wavelet 
$2 \times 0.024095462=0 ., 048190924$ and second fluctuation $2 \times 0.13093392=0.26186784$ (it is necessary to consider still a multiplier $10^{-22}$ ).

The attitude of the second fluctuation towards the first will be equal 5.43398. Frequency of two fluctuations of a gravitational wave under a condition $T=0$ at the possible pulsar which is infinitely quickly rotating theoretically will be equal $20.750805 \mathrm{e} 22$ and $3.818721 \mathrm{e} 22$.

To two aperiodic fluctuations of a trend which were expressed by the modified Laplace's laws, two asymmetric wavelet are added.

\section{Conclusion}

We proved possibility of a solution of the problem of development of methods of calculus of variations (Hilbert's 23rd problem) in its separate part (having excluded abstract mathematics), in relation to statistical modeling of tables according to measurements. Hilbert's bricks which are reduced to the biotechnical law were for this purpose received. They allow to design the generalized algebraic equation according to Descartes in the form of the sum asymmetric wavelets with variables amplitude and the fluctuation period.

The methodology and technology of identification of any natural phenomena and processes is created. Thus the casual choice of the equations is excluded and replaced with conscious selection of a design of statistical model by way of accumulation of the sum of members in the form of a set asymmetric wavelets with variables amplitude and the fluctuation period.

Therefore on the computer only the stage of parametrical identification of the increased sum of members in the form of asymmetric wavelet signals is realized. However the program CurveExpert environment for such identification approaches a little: process very labor-consuming at selection of a design of certain members of model. Thus the program CurveExpert environment is limited by number of at the same time identified model parameters. Therefore according to our scenarios it is necessary to create specially the new program environment for its application on supercomputers.

Applicability of statistical model (1) to any natural objects, first of all to biological $[22,23]$ and biotechnical is proved, beginning from an impulse of heart of the person to model of the lapping Universe. For example, in gravitational waves between the Sun, Earth and the Moon in the period of a maximum of a solar eclipse there are multilevel processes which can precisely be caught on hour increments of impulses of alpha decay from a sample ${ }^{239} \mathrm{Pu}$.

And, at last, there is a group of regularities, on the remains comparable with a margin error measurements. This fact proves that the method of measurement of indignations of gravitational waves of the device with alpha decay impulses ${ }^{239} \mathrm{Pu}$ is very exact, allowing to carry out registration on separate impulses.

\section{References}

[1] Brummelen, G. V., Kinyon, M. Mathematics and the Historian's Craft. The Kenneth O. May Lectures. 2005. Springer Science, Business Media, Inc. Library of Congress Control Number: 2005923503. bok\%3A978-0-387-28272-5.pdf.

[2] Corry, L. Archive for History of Exact Sciences. Chapter: David Hilbert and the Axiomatization of Physics (1894-1905). Springer-Verlag, 1997. P. 83-198. DOI 10.1007/BF00375141. 
[3] Corry, L. Modern Algebra and the Rise of the Mathematical Structures. Chapter 3. David Hilbert: Algebra and Axiomatics. Birkhäuser Basel, 2004. P.137-182. DOI 10.1007/978-3-0348-7917-0_4.

[4] Invariant theory. Algebraic number fields. Axiomatic. Integral equations. Physics. URL: http://www.ega-math.narod.ru/Reid/Weyl.htm \# ch1.

[5] Progress in Mathematics. Volume 280. Series Editors H. Bass, J. Oesterle, A. Weinstein // Liaison, Schottky problem and Invariant Theory. Remembering Federico Gaeta. Maria Emilia Alonso, Enrique Arrondo, Raquel Mallavibarrena, Ignacio Sols, Editors. Birkhauser. 2010. Springer Basel AG. bok\%3A978-3-0346-0201-3.pdf.

[6] Rowe, D. E. Hilberrs Early Career: Encounters with Allies and Rivals. THE MATHEMATICAL INTELLIGENCER_9, 2005. Spnnger Science+Business Media. Inc. art\%3A10.1007\%2FBF02984817.pdfHilberrs.

[7] Mazurkin, P. M. Invariants of the Hilbert Transform for 23-Hilbert Problem, Advances in Sciences and Humanities. Vol. 1, No. 1, 2015. P. 1-12. doi: 10.11648/j.ash.20150101.11.

[8] Mazurkin P. M. Riemann's Hypothesis and Critical Line of Prime Numbers, Advances in Sciences and Humanities. Vol. 1, No. 1, 2015, P. 13-29. doi: 10.11648/j.ash.20150101.12.

[9] Mazurkin P. M. Wavelet Analysis Statistical Data. Advances in Sciences and Humanities. Vol. 1, No. 2, 2015, pp. 30-44. doi: 10.11648/j.ash.20150102.11.

[10] Mazurkin P. M. Method of Identification of Wave Regularities According to Statistical Data (Of Dynamics of a Rate of Inflation of US Dollar). Advances in Sciences and Humanitie. Vol. 1, No. 2, 2015, P. 45-51. doi: 10.11648/j.ash.20150102.12.

[11] Mazurkin, P. M. Wavelet analysis of hour increments of alpha activity ${ }^{239} \mathrm{Pu}$ at a maximum of a solar eclipse // Science and the world: international scientific magazine. 2014. No. 2(6). Volume 1. P. 46-55.

[12] Mazurkin, P. M. Wavelet analysis of hour increments of alpha activity ${ }^{239} \mathrm{Pu}$ after a solar eclipse // Science and the world: international scientific magazine. 2014. No. 3(7). Volume 1. Page 31-40.

[13] Mazurkin, P. M. Wavelet analysis of crisis dynamics of ruble exchange rate // Interdisciplinary researches in the field of mathematical modeling and informatics. Materials of the 3rd scientific and practical Internet conference. Ulyanovsk: SIMJET, 2014. Page 260-268.

[14] Mazurkin, P. M. Asymmetric Wavelet Signal of Gravitational Waves, Applied Mathematics and Physics, vol. 2, No. 4 (2014). P. 128-134. doi: 10.12691/amp-2-4-2.

[15] Mazurkin, P. M. Wavelet Analysis of a Number of Prime Numbers, American Journal of Numerical Analysis, vol. 2, No. 2 (2014). P. 29-34. doi: 10.12691/ajna-2-2-1.

[16] Mazurkin P. M., Tishin D. V. Wave dynamics of tree-ring width jf Oak, Integrated Journal of British. Volume 2. 2015. Issue 1. JAN-FEB. P. 55-67. IJBRITISH-223-PA.pdf. 